\title{
Multi-Attribute Decision Making using Hybrid Approach based on Benefit Cost Model for Sustainable Fashion
}

\author{
Adriyendi ${ }^{1}$, Yeni Melia ${ }^{2}$ \\ ${ }^{1}$ Informatics Group, IAIN Batusangkar, Indonesia \\ ${ }^{2}$ Economics Group, IAIN Batusangkar, Indonesia
}



This is an open access article under the CC BY-SA license.

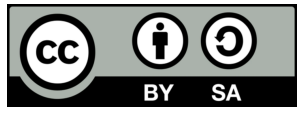

\section{Corresponding Author:}

Adriyendi,

Informatics Group,

IAIN Batusangkar,

Batusangkar-Padangpanjang Road Km 7, Batusangkar 27212, Indonesia

Email: elektronikpos@gmail.com

\section{INTRODUCTION}

Sustainable fashion is based on the use of clothing with long-term durability, high-quality stitching, production ethics, and environmental friendliness. Quality is considered as the main priority compared to production speed and quantity. Sustainable fashion is not only in the aspects of materials used and the environments that are affected, but also in the use of the most up to date, recyclable, and repaired materials [1]. Sustainable fashion is very profitable for producers to market their products to the growing middle-class community in Indonesia. The middle-class consists of professionals, industrialists and small entrepreneurs in the informal sector. With the population in Indonesia around 128.51 million [2], this population has become a very significant market for producers in increasing sustainable fashion production. Sustainable fashion production in many choices provides a great opportunity as an alternative for both producers and consumers. Sustainable fashion is clothing with the basic ingredients of natural fibers and artificial fibers. Natural fibers are cotton, linen, wool and silk. Sustainable fashion is clothing with materials from artificial fibers (man-made fibers) such as rayon, nylon, polyester, spandex, and acrylic. The main ingredients of sustainable fashion are plants, animals, and synthetics in the form of natural fibers and artificial fibers [3], each of which have different impacts on producers and consumers. For producers, it is necessary to have many materials available for high productivity and sustainable production. As a matter of fact, these materials are available in limited quantities. For consumers, limited ingredients certainly have high prices, few supplies, and dependent on consumers' 
needs and wants. Market mechanisms require productivity with fashion patterns are quickly ready, while the purchasing power of consumers with high-style characters and fashion patterns is in line with fashion trends. Multi-alternative (fashion material) and multi-criteria (clothing characteristics) are important multi-attributes (alternatives and criteria) for the sustainable fashion industry. Therefore, appropriate methods and optimal solutions are needed to determine the best multi-attribute choices in decision making for producers and consumers. Researchers have proposed many methods, one of which is Multi-Attribute Decision Making [4]. Multi-Attribute Decision-Making (MADM) is a decision making method that involves many attributes with many criteria for many alternatives to one objective function. MADM is used to solve problems in discrete spaces. MADM is used to choose the best alternative with multi-attributes in the amount of data available. This method has been proposed and supported by many researchers. Popular MADM models include Simple MultiAttribute Rating (SMART), Multi-Factor Evaluation Process (MFEP), Multi-Object Optimization based on Ratio Base Analysis (MOORA), Simple Additive Weighting (SAW), Weighted Product (WP), and many the others. SMART is an optimization analysis model using a linear additive model to predict the value of each alternative. SMART is a simple, flexible, transparent, and fast-responding method to support decision-making and is acceptable to decision-makers [5]. MFEP is a quantitative method that uses a weighting system with a significant influence in strategic decision-making [6]. MOORA has advantages in simple calculations, has a cost value (minimum value), a benefit value (maximum value), has a good level of selectivity because it can determine the objectives of conflicting criteria [7]. The SAW model has advantages in evaluating preference and normalizing matrices more precisely based on conflicting attribute values, benefit values and cost values [8]. The WP model has the advantage of being faster in the decision-making process and highly precise in calculating the ranking of each decision attribute, with ranking on each attribute with weights for each alternative based on conflicting attribute values namely: benefit and cost [9].

Clothing attributes have been proposed by many researchers. Based on the paper [9], recommendations proposed for women's clothing by the Naïve Bayes method employs the multi-attributes: style, price, rating, size, season, neckline, arm length, fabric type, decoration, pattern-type, and recommendations. Based on the paper [11], the proposed attributes of women's clothing using the Customer Value Index method with multiattributes: style, country of origin, brand, price, and ethical attributes. Based on the paper [12], it is proposed that Clothing Quality uses the Analytical Hierarchy Process method using multi-attributes: fabric quality, seams, and size. The multi-attribute approach has been proposed by many researchers. Based on the paper [13], multi-attribute decision-making is proposed using the SAW Model and WP Model to evaluate the optimal generation of clothing and clothing on certain days. Based on the paper [14], multi-attribute decision-making is proposed using the MFEP Model and the SMART Model for suitability of clothing for coastal tourism areas.

In this paper, a multi-attribute model is proposed using the SMART Model, the MFEP Model, the MOORA Model, the SAW Model, and the WP Model for sustainable fashion. The multi-criteria of sustainable fashion in general are high water absorption, good gradation, and convincing product durability. In this paper, the proposed criteria are material fiber, smooth texture, fade color, elastic clothing, chilly \& comfortable, and usable long. The proposed multi-attributes for sustainable fashion are material, texture, color, characteristics, comfort, and wearability. Multi-attribute decision-making generally has one objective function. The generally used objective functions are the maximum function or minimum function. In this paper, it is proposed that the process of multi-attribute decision-making is carried out with more than one objective function (multiobjective), which is to combine the maximum objective function and minimum objective function.

To obtain a solution to the problem of sustainable fashion for producers and consumers, multi-attribute decision-making with multi-criteria and multi-alternatives for one objective function, in this paper, the application of multi-attribute decision-making employs multi-criteria and multi-alternative with multiobjective (maximum objective function and minimum objective function, two in one process simultaneously). The attributes for maximum objective function are material, texture, color, characteristic, and comfort, while the attribute of minimum function for attributes is wearability. The proposed models for the MADM process are SMART and MFEP for the application of the maximum objective function, while MOORA, SAW, and WP for the application of the minimum objective function. The application of the SMART, MFEP, MOORA, SAW, and WP models are used as a Hybrid Approach for Multi-Objective functions in the decision-making process. The main contribution of this paper are summarized as follows:

- Multi-Attribute Decision Making (MADM) by using hybrid approach (SMART, MFEP, MOORA, SAW, and WP) for multi-objective functions (benefit and cost).

- Implementation SMART and MFEP used to maximum objective function (benefit) in one process simultaneously while MOORA, SAW, and WP used to maximum and minimum objective function (benefit and cost), two in one process simultaneously.

- MADM by using hybrid approach for sustainable fashion yields the best alternative (rayon) for consumption and production for the middle-class population in Indonesia. 


\section{RESEARCH METHOD}

This section discusses the concept of Multi-Attribute Decision-Making (MADM), SMART Model, MFEP Model, MOORA Model, SAW Model, WP Model, and Sustainable Fashion.

\subsection{MADM}

Multi-Attribute Decision-Making (MADM) is used for situational, analytical, and synthetical components, with aggregation and alternative ranking for information processing. The MADM Model is done by evaluating the alternative $A_{i}(i=1,2, \ldots, m)$ for a set of attributes or $C_{j}$ criteria $(j=1,2, \ldots, n)$, the weighting factor $W_{j}$ on the decision matrix of each alternative for each attribute $X$ with formula based on paper [15].

$$
\begin{aligned}
& X=\left\{\begin{array}{ccccc}
x_{11} & x_{12} & \ldots \ldots & x_{1 n} \\
x_{21} & x_{22} & \ldots . & x_{2 n} \\
\cdots & \ldots & \ldots & \ldots \\
x_{m 1} & x_{m 2} & \cdots & \ldots & x_{m n}
\end{array}\right\} \\
& A=\left\{a_{i} \mid i=1,2 ., 3, \ldots n\right\} \\
& C=\left\{c_{j} \mid j=1,2 ., 3, \ldots m\right\} \\
& W=\left\{w_{1}, w_{2}, w_{3}, \ldots n\right\}
\end{aligned}
$$

where $A_{1}, A_{2}, \ldots, A_{n}$ are feasible alternatives, $C_{l}, C_{2}, \ldots, C_{n}$ is the attribute (criterion), $X_{i j}$ is the $i$-th alternative performance rank with respect to $j$-th attribute, and $W_{j}$ is the weight (significance) of $j$-th attribute.

\subsection{SMART Model}

SMART is a multi-alternative decision-making method with weights and normalization using a certain scale. Each attribute has weight compared to the weights on the other attributes for each alternative. Steps of the SMART Model based on the paper [16].

Step 1: determine the criteria and alternatives.

Step 2: determine a scale of 0 to 100 and total based on priority criteria.

Step 3: determine the weight with a total weight of 1 , dividing the scale value by the total scale value.

Step 4: normalize the weight (W) with the formula:

$$
W=\frac{w_{j}}{\sum w_{j}}
$$

Step 5: enter the value of each criterion in each alternative.

Step 6: calculate the utility value $\left(u_{i}\right)$ for each criterion for each attribute $\left(a_{i}\right)$ based on the weight $\left(w_{j}\right)$.

$$
u_{i}\left(a_{i}\right)=\sum_{J=1}^{m} w_{j} u_{i}\left(a_{i}\right)
$$

Step 7: calculate the final value of each criterion for each alternative. The best results are the highest scores of all the final scores from each alternative available.

\subsection{MFEP Model}

MFEP is multi-attribute, multi-alternative, multi-factor decision making by considering each factor based on the importance of each criterion for each alternative. Steps of the MFEP Model based on the paper [17].

Step 1: determine the criteria and alternatives.

Step 2: determine the weights (W) on each criterion with a scale between 0 and 1 with a total $=1$. Step 3: enter the value of each criterion for each alternative.

Step 4: calculate the weight evaluation value $(V(w e)$ with the formula:

$V(w e)=v(w f) * v(e f)$

Where $V(w e)$ is the weight evaluation value, $v(w f)$ is the weight factor value, and $v(e f)$ is the evaluation factor value.

Step 5: calculate the total evaluation value using the formula:

$$
T(v e)=V\left(w e_{1}\right)+V\left(w e_{2}\right)+\cdots V\left(w e_{n}\right)
$$

Where $T(v e)$ is the total evaluation value and $V$ is the weight evaluation value $-n$.

Step 6: calculate the final value of each criterion for each alternative. The best results are the highest scores of all the final scores from each alternative available.

\subsection{MOORA Model}

MOORA is a method of optimization decision-making by maximizing the selection of each alternative according to the differences in each criterion in each problem simultaneously. This method is flexible in separating objects, and selective in determining objectives and conflicting criteria, namely criteria that have a 
maximum value (Benefits) and criteria that have a minimum value (Costs). Steps of the MOORA Model based on the paper [18].

Step 1: determine the criteria and alternatives

Step 2: determine factors and weighting factors with a scale between 0 and 1 with a total $=1$

Step 3: enter the value of each criterion for each alternative

Step 4: determine the type of weight factor by the type of benefit (weight factor criteria with maximum value) and cost type (weight factor criteria with minimum value).

Step 5: normalize attributes with the square root of the sum of squares of each alternative per attribute with the formula:

$$
X_{i j}=\frac{x_{i j}}{\sqrt{\left[\sum_{i j}^{m} x_{i j}^{2}\right](j=1,2, \ldots, n)}}
$$

Where $X_{i j}$ is a matrix where $i$ is the value of each alternative, $m$ is the number of alternatives, and $j$ is the number of criteria.

Step 6: The multi-objective optimization process, by maximizing the sum of the beneficial attributes (benefits) and minimizing the reduction of unfavorable attributes (cost) with the formula:

$$
Y_{i}=\sum_{j=1}^{g} w_{j} x_{i j} \sum_{j=g+1}^{n} w_{j} x_{i j}
$$

Where $g$ is the number of attributes that must be maximized, $(n-g)$ is the number of attributes that must be minimized, and $Y_{i}$ is the normal value of the alternative values for all attributes.

Step 7: calculate the final value of each criterion for each alternative. The best results are the highest scores of all the final scores from each alternative available.

\subsection{SAW Model}

SAW is a method in evaluating preference and normalizing matrices more precisely based on conflicting attribute values, benefit values, and cost values. Steps of SAW Model based on the paper [19].

Step 1: determine the criteria and alternatives

Step 2: determine factors and weight factors with the total weighting factor being 1

Step 3: determine the type of weight factor by the type of benefit (weight factor criteria with maximum value) and cost type (weight factor criteria with minimum value).

Step 4: enter the value of each criterion for each alternative

Step 5: rank the divider value based on the maximum value of the type of benefit and the minimum value for the type of cost.

Step 6: normalize the value of each criterion for the value of each alternative based on the type of benefit and the type of cost using the formula:

$$
R_{i j}=\left\{\frac{\frac{x_{i j}}{\max _{x_{i j}}}}{\frac{\min _{x_{i j}}}{x_{i j}}}\right\}
$$

Where $R_{i j}$ is a normalized rank, $X_{i j}$ is the attribute of each criterion for each alternative, $\max x_{i j}$ is the maximum value, and $\min x_{i j}$ is the minimum value.

Step 7: calculate the ranking value of each alternative using the formula:

$$
V_{i}=\sum_{j=1}^{n} W_{j} R_{i j}
$$

Where $V_{i}$ is ranked for each alternative, $W_{j}$ is the weighted value of each criterion, and $R_{i j}$ is a normalized performance rating value

Step 8: calculate the final value of each criterion for each alternative. The final value of the ranking process is the sum of the normalized matrix multiplications with the weight vectors. The best results are the highest scores of all the final scores from each alternative available.

\subsection{WP Model}

The WP is a method in the decision-making process and highly precise in calculating the ranking of each decision attribute, with ranking on each attribute with weights for each alternative based on conflicting attribute values namely: benefit and cost. Steps of the WP Model based on the paper [20].

Step 1: determine the criteria and alternatives

Step 2: determine a scale of 0 to 100 and total based on priority criteria 
Step 3: determine the factors and weight factors by the total weighting factor is 1 by dividing the scale value by the total scale value

Step 4: enter the value of each criterion for each alternative

Step 5: calculate alternative preference values using the formula:

$$
S_{i}=\prod_{j=1}^{n} X_{i j} w j
$$

Where $S_{i}$ alternative preferences are to vectors, $X_{i j}$ is value criteria, $w$ is a weight criterion, $n$ is a number of criteria, $i$ is an alternative criterion and $j$. Then, the next step is normalization using Equation (5).

Step 6: calculate the vector value $\left(V_{i}\right)$ for each alternative using the formula:

$$
V_{i}=\frac{\prod_{j}^{n} 1^{x i j^{w j}}}{\prod_{j}^{n} X_{j} w_{j}}
$$

Where $V_{i}$ is vector value, $X_{i j}$ is a value criterion, $n$ is a number of criteria, $w$ is a weighting criterion, $i$ is an alternative, and criteria $j$.

Step 7: calculate the final value of each criterion for each alternative. The best results are the highest scores of all the final scores from each alternative available.

\subsection{Sustainable Fashion}

Sustainable fashion is the concept of a sustainable design chain. Fashion products are designed and manufactured with consideration of the environment and the social impact it causes. Sustainable fashion is part of a developing design philosophy with the aim of creating a system that can reduce environmental damage due to the production and consumption of clothing [21]. Multi-alternatives to sustainable fashion are natural fibers and artificial fibers (man-made fibers). Natural fibers are derived from a source such as cotton, linen, silk, and wool, while artificial fibers with a source of material from acrylic, nylon, polyester, rayon, spandex, and mixed. The two types of fibers come from plants (cotton, linen, wood, and bamboo), animals (silk and wool), and synthetics (acrylic, nylon, polyester, rayon, spandex, and mixed). MADM for sustainable fashion can be described in the form of a framework shown in Figure 1.

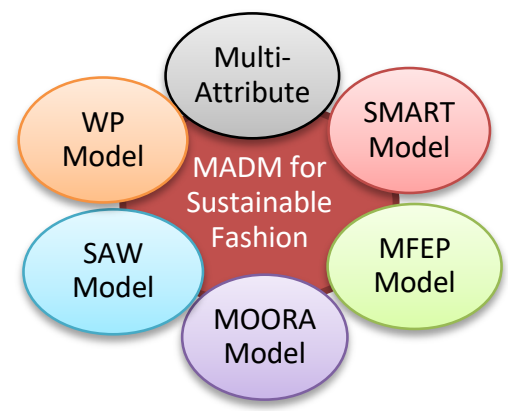

Figure 1. Framework MADM for Sustainable Fashion

\section{RESULTS AND DISCUSSION}

This section discusses the application of Multi-Attribute Decision-Making (MADM), SMART Model, MFEP Model, MOORA Model, SAW Model, and WP Model for Sustainable Fashion.

\subsection{MADM} Table 2 .

Multi-Attribute Decision Making (MADM) uses alternatives and attributes shown in Table 1 and

Table 1. Alternatives

\begin{tabular}{llllllllll}
\hline No. & Alternative & No. & Alternative & No. & Alternative & No. & Alternative & No. & Alternative \\
\hline 1 & Acrylic & 3 & Linen & 5 & Nylon & 7 & Rayon & 9 & Spandex \\
2 & Cotton & 4 & Mix & 6 & Polyester & 8 & Silk & 10 & Wool \\
\hline
\end{tabular}

Table 1 shows multi-alternatives consisting of natural fibers (cotton, linen, silk, and wool) and artificial fibers (acrylic, nylon, polyester, rayon, spandex, and mixed) while Table 2 shows multi-attributes with 6 criteria, input weights using random numbers, weights normalized using random numbers, and ranking values based on criteria. 
Table 2. Attributes

\begin{tabular}{llll}
\hline Criteria & Weight & Normalization & Attribute Value \\
\hline Material (A) & 2.4000 & 0.1600 & Fiber $=3$, Leather $=2$, Synthetic $=1$, Smooth $=4$ \\
Texture (B) & 2.2500 & 0.1500 & Endurance $=3$, Light in Weight $=2$, Coarse $=1$ \\
Color (C) & 2.3000 & 0.1533 & Bright $=3$, Fade $=2$, Dark $=1$ \\
Characteristic (D) & 2.7500 & 0.1833 & Elastic $=4$, Absorbent $=3$, Glossy $=2$, Rumpled $=1$ \\
Comfort (E) & 2.6000 & 0.1733 & Chilly $=3$, Warm $=2$, Sultry $=1$ \\
Wearability (F) & 2.7000 & 0.1800 & Very High $=1$, High $=2$, Middle $=3$, Low $=4$ \\
\hline
\end{tabular}

The weights are entered based on Equation (4) and total $=15$ using the formula Excel =SUM(C6:H6). Input weights are normalized based on Equation (4) and total $=1$ using the formula Excel $=\mathrm{SUM}(\mathrm{C} 7: \mathrm{H} 7)$. Normalization weight uses the formula Excel $=\mathrm{C} 6 / \mathrm{S} 6=0.1600$ for material criteria based on Equation (5). In the same method do the criteria: texture, color, characteristics, comfort, and wearability.

Table 3. Values

\begin{tabular}{lcccccc}
\hline Alternative/Criteria & Material & Texture & Color & Characteristic & Comfort & Wearability \\
\hline Acrylic & $\mathrm{X}_{11}=1$ & $\mathrm{X}_{12}=4$ & $\mathrm{X}_{13}=2$ & $\mathrm{X}_{14}=4$ & $\mathrm{X}_{15}=2$ & $\mathrm{X}_{16}=3$ \\
Cotton & $\mathrm{X}_{21}=3$ & $\mathrm{X}_{22}=4$ & $\mathrm{X}_{23}=2$ & $\mathrm{X}_{24}=1$ & $\mathrm{X}_{25}=3$ & $\mathrm{X}_{26}=4$ \\
Linen & $\mathrm{X}_{31}=3$ & $\mathrm{X}_{32}=3$ & $\mathrm{X}_{33}=2$ & $\mathrm{X}_{34}=1$ & $\mathrm{X}_{35}=3$ & $\mathrm{X}_{36}=3$ \\
Mix & $\mathrm{X}_{41}=1$ & $\mathrm{X}_{42}=2$ & $\mathrm{X}_{43}=3$ & $\mathrm{X}_{44}=3$ & $\mathrm{X}_{45}=2$ & $\mathrm{X}_{46}=3$ \\
Xylon & $\mathrm{X}_{51}=1$ & $\mathrm{X}_{52}=2$ & $\mathrm{X}_{53}=3$ & $\mathrm{X}_{54}=4$ & $\mathrm{X}_{55}=1$ & $\mathrm{X}_{56}=2$ \\
Polyester & $\mathrm{X}_{61}=1$ & $\mathrm{X}_{62}=2$ & $\mathrm{X}_{63}=3$ & $\mathrm{X}_{64}=2$ & $\mathrm{X}_{65}=2$ & $\mathrm{X}_{66}=3$ \\
Rayon & $\mathrm{X}_{71}=1$ & $\mathrm{X}_{72}=4$ & $\mathrm{X}_{73}=3$ & $\mathrm{X}_{74}=4$ & $\mathrm{X}_{75}=3$ & $\mathrm{X}_{76}=2$ \\
Silk & $\mathrm{X}_{81}=2$ & $\mathrm{X}_{82}=2$ & $\mathrm{X}_{83}=3$ & $\mathrm{X}_{84}=2$ & $\mathrm{X}_{85}=2$ & $\mathrm{X}_{86}=4$ \\
Spandex & $\mathrm{X}_{91}=1$ & $\mathrm{X}_{92}=2$ & $\mathrm{X}_{92}=3$ & $\mathrm{X}_{94}=4$ & $\mathrm{X}_{95}=2$ & $\mathrm{X}_{96}=3$ \\
Wool & $\mathrm{X}_{101}=2$ & $\mathrm{X}_{102}=3$ & $\mathrm{X}_{103}=1$ & $\mathrm{X}_{104}=3$ & $\mathrm{X}_{105}=2$ & $\mathrm{X}_{106}=3$ \\
\hline
\end{tabular}

Table 3 shows the values for each criterion for each alternative in the decision matrix based on Equation (1).

\subsection{SMART Model}

The SMART Model uses alternatives based on Table 1 and attribute-based on Table 2. Step 1: determine criteria and alternatives-based Equation $(1,2,3)$ which can be seen in Table 1 and Table 2. Step 2: determine the scale of 0 to 100 and total based on priority criteria using random number with a value 2,400 for material criteria up to wearability criteria which can be used with a value of 2.2700 with a total $=15$ based on Equation (4) shown in Table 2. Step 3: determine the normalization of weights with total weights of 1 by dividing the scale value by the total scale value shown in Table 2. Step 4: based on weight normalization equation (W) (5) that can be seen in Table 2. Step 5: enter the value of each criterion for each alternative based on the decision matrix shown in Table 4.

Table 4. Input SMART Model

\begin{tabular}{lcccccc}
\hline Weight & 2.400 & 2.2500 & 2.3000 & 2.7500 & 2.6000 & 2.7000 \\
\hline Normalization & 0.1600 & 0.1500 & 0.1533 & 0.1833 & 0.1733 & 0.1800 \\
Criteria/Alternative & Material & Texture & Color & Characteristic & Comfort & Wearability \\
Acrylic & 1 & 4 & 2 & 4 & 2 & 3 \\
Cotton & 3 & 4 & 2 & 1 & 3 & 4 \\
Linen & 3 & 3 & 2 & 1 & 3 & 3 \\
Mix & 1 & 2 & 3 & 3 & 2 & 3 \\
Nylon & 1 & 2 & 3 & 4 & 1 & 2 \\
Polyester & 1 & 2 & 3 & 2 & 2 & 3 \\
Rayon & 1 & 4 & 3 & 4 & 3 & 2 \\
Silk & 2 & 2 & 3 & 2 & 2 & 4 \\
Spandex & 1 & 2 & 3 & 4 & 2 & 3 \\
Wool & 2 & 3 & 1 & 3 & 2 & 3 \\
\hline
\end{tabular}


Step 6: calculate the utility (ui) value for each criterion for each attribute (ai) based on weights (wj) based on Equation (6) in Excel formula $=(\mathrm{C} 10 * \mathrm{C} \$ 7)+(\mathrm{D} 10 * \mathrm{D} \$ 7)+(\mathrm{E} 10 * \mathrm{E} \$ 7)+(\mathrm{F} 10 * \mathrm{~F} \$ 7)+(\mathrm{G} 10 * \mathrm{G} \$ 7)+(\mathrm{H} 10 * \mathrm{H} \$ 7)$, for Alternative Acrylic with a value of 2.6867. The same method is also applied to each other alternatives shown in Table 5. Table 5 shown output values in the SMART Model.

Table 5. Output SMART Model

\begin{tabular}{cccc}
\hline Alternative MCDM & Total & Sort & Alternative SMART \\
\hline Acrylic & 2.6867 & 2.8333 & Rayon \\
Cotton & 2.8100 & 2.8100 & Cotton \\
Linen & 2.4800 & 2.6867 & Acrylic \\
Nylon & 2.3567 & 2.5400 & Spandex \\
Polyester & 2.1867 & 2.5133 & Silk \\
Mix & 2.1733 & 2.4800 & Linen \\
Rayon & 2.8333 & 2.3600 & Wool \\
Silk & 2.5133 & 2.3567 & Nylon \\
Spandex & 2.5400 & 2.1867 & Polyester \\
Wool & 2.3600 & 2.1733 & Mix \\
\hline
\end{tabular}

Step 7: calculate the final value of each criterion for each alternative. The total values in Table 5 are sorted by Sort based on the Descending process. c, which is Alternative Rayon with a value of 2.8333. Therefore, Rayon was chosen as the best alternative from alternatives based on the SMART Model.

\subsection{MFEP Model}

The MFEP Model uses alternatives based on Table 1 and attribute-based on Table 2. Step 1: determine criteria and alternatives based Equation $(1,2,3)$ which can be seen in Table 1 and Table 2. Step 2: determine the weights $(\mathrm{W})$ of each criterion on a scale between 0 and 1 with a total $=1$. The Input weight based on Equation (4) and normalization can be seen in Table 2. Step 3: enter the value of each criterion for each alternative based on the decision matrix (Table 3) shown in Table 6. Table 6 shows the input values for alternatives based on the attribute values in Table 2. Step 4: calculate the weight evaluation value (V) based on Equation (7) in Excel formula $=$ C9 $*$ C \$ 7 for Alternative Acrylic with a value $=0.1600$. The same method is also used for Alternative Cotton to Alternative Wool. Display output values in Table 7.

Table 7. Output 1 MFEP Model

\begin{tabular}{lcccccc}
\hline Alternative & Material & Texture & Color & Characteristic & Comfort & Wearability \\
\hline Acrylic & 0.1600 & 0.6000 & 0.3066 & 0.7332 & 0.3466 & 0.5400 \\
Cotton & 0.4800 & 0.6000 & 0.3066 & 0.1833 & 0.5199 & 0.7200 \\
Linen & 0.4800 & 0.4500 & 0.3066 & 0.1833 & 0.5199 & 0.5400 \\
Mix & 0.1600 & 0.3000 & 0.4599 & 0.5499 & 0.3466 & 0.5400 \\
Nylon & 0.1600 & 0.3000 & 0.4599 & 0.7332 & 0.1733 & 0.3600 \\
Polyester & 0.1600 & 0.3000 & 0.4599 & 0.3666 & 0.3466 & 0.5400 \\
Rayon & 0.1600 & 0.6000 & 0.4599 & 0.7332 & 0.5199 & 0.3600 \\
Silk & 0.3200 & 0.3000 & 0.4599 & 0.3666 & 0.3466 & 0.7200 \\
Spandex & 0.1600 & 0.3000 & 0.4599 & 0.7332 & 0.3466 & 0.5400 \\
Wool & 0.3200 & 0.4500 & 0.1533 & 0.5499 & 0.3466 & 0.5400 \\
\hline
\end{tabular}

Step 5: calculate the total evaluation value based on Equation (8) in Excel formula $=\mathrm{SUM}(\mathrm{C} 22: \mathrm{H} 22)$ for Alternative Acrylic with value $=2.6864$. The same method is also used in alternative Cotton to Alternative Wool. The total output can be seen in Table 8 . Table 8 shows the output with the highest value is Rayon as the best alternative in the MFEP Model. Step 6: calculate the final value of each criterion. The total values in Table 8 are sorted by Sort based on the Descending process. The best results are the highest value which Alternative Rayon with a value of 2.8330. Therefore, Rayon was chosen as the best alternative from alternatives based on the MFEP Model. 
Table 8. Output 2 MFEP Model

\begin{tabular}{cccc}
\hline Alternative MCDM & Total & Sort & Alternative MFEP \\
\hline Acrylic & 2.6864 & 2.8330 & Rayon \\
Cotton & 2.8098 & 2.8098 & Cotton \\
Linen & 2.4798 & 2.6864 & Acrylic \\
Mix & 2.3564 & 2.5397 & Spandex \\
Nylon & 2.1864 & 2.5131 & Silk \\
Polyester & 2.1731 & 2.4798 & Linen \\
Rayon & 2.8330 & 2.3598 & Wool \\
Silk & 2.5131 & 2.3564 & Mix \\
Spandex & 2.5397 & 2.1864 & Nylon \\
Wool & 2.3598 & 2.1731 & Polyester \\
\hline
\end{tabular}

The best results are the highest value which Alternative Rayon with a value of 2.8330 . The best alternative is rayon based on the MFEP Model.

\subsection{MOORA Model}

The MOORA Model uses alternatives based on Table 1 and attribute-based on Table 2. Step 1: determine criteria and alternatives based Equation $(1,2,3)$ which can be seen in Table 1 and Table 2. Step 2: determine the factors and weighting factors with a scale between 0 and 1 with a total $=1$. Input weights based on Equation (4) and normalization can be seen in Table 2. Step 3: enter the value of each criterion for each alternative based on the decision matrix (Table 3). Input values in the MOORA model can be seen in Table 9.

Table 9. Input MOORA Model

\begin{tabular}{lcccccc}
\hline Type & Benefit & Benefit & Benefit & Benefit & Benefit & Cost \\
\hline Normalization & 0.1600 & 0.1500 & 0.1533 & 0.1833 & 0.1733 & 0.1800 \\
Criteria/Alternative & Material & Texture & Color & Characteristic & Comfort & Wearability \\
Acrylic & 1 & 4 & 2 & 4 & 2 & 3 \\
Cotton & 3 & 4 & 2 & 1 & 3 & 4 \\
Linen & 3 & 3 & 2 & 1 & 3 & 3 \\
Mix & 1 & 2 & 3 & 3 & 2 & 3 \\
Nylon & 1 & 2 & 3 & 4 & 1 & 2 \\
Polyester & 1 & 2 & 3 & 2 & 2 & 3 \\
Rayon & 1 & 4 & 3 & 4 & 3 & 2 \\
Silk & 2 & 2 & 3 & 2 & 2 & 4 \\
Spandex & 1 & 2 & 3 & 4 & 2 & 3 \\
Wool & 2 & 3 & 1 & 3 & 2 & 3 \\
\hline
\end{tabular}

Step 4: determine the type of weight factor by the type of benefit (weight factor criteria with maximum value) and the type of cost (weight factor criteria with minimum value). Types of Benefits and costs display type in Table 9. Step 5: normalize attributes with square root of the sum of squares of each alternative per attribute based on Equation (9) in Excel formula $=\mathrm{C} 7 / \mathrm{SQRT}\left(\mathrm{C} \$ 7^{\wedge} 2+\mathrm{C} \$ 8^{\wedge} 2+\mathrm{C} \$ 9^{\wedge} 2+\mathrm{C} \$ 10^{\wedge} 2+\mathrm{C} \$ 11^{\wedge} 2+\mathrm{C} \$ 12^{\wedge} 2^{2}+\mathrm{C} \$ 13^{\wedge}\right.$ $\left.2+\mathrm{C} \$ 14^{\wedge} 2+\mathrm{C} \$ 15^{\wedge} 2+\mathrm{C} \$ 16^{\wedge} 2\right)$ for Alternative Acrylic with a value of 0.1768 . The same method is also used in Alternative Cotton to Alternative Wool. Output is shown in Table 10. Table 10 shows the values based on type, criteria, weight, and normalization. Step 6: The multi-objective optimization process, by maximizing the addition of beneficial attributes and minimizing the reduction of unfavorable attributes in Excel formula $=\mathrm{IF}(\mathrm{K} \$ 18=$ "cost", $-1 * \mathrm{C} 20 * \mathrm{~K} \$ 19, \mathrm{C} 20 * \mathrm{~K} \$ 19)$ for Alternative Acrylic with a value of 0.0283 . The same method is also used in Alternative Cotton to Alternative Wool. The output is shown in Table 11. Table 11 shows the output values based on the type, criteria, weight of update, and update normalization. Step 7: calculate the final value of each criterion for each alternative. Final value with the total in the formula Excel = SUM(K20: P20) for Alternative Acrylic with a value $=0.1977$. The same method is also used in alternative Cotton to Alternative Wool. 
Table 10. Output 1 MOORA Model

\begin{tabular}{lcccccc}
\hline Criteria/Alternative & Material & Texture & Color & Characteristic & Comfort & Wearability \\
\hline Acrylic & 0.1768 & 0.4313 & 0.2443 & 0.4170 & 0.2774 & 0.3180 \\
Cotton & 0.5303 & 0.4313 & 0.2443 & 0.1043 & 0.4160 & 0.4240 \\
Linen & 0.5303 & 0.3235 & 0.2443 & 0.1043 & 0.4160 & 0.3180 \\
Mix & 0.1768 & 0.2157 & 0.3665 & 0.3128 & 0.2774 & 0.3180 \\
Nylon & 0.1768 & 0.2157 & 0.3665 & 0.4170 & 0.1387 & 0.2120 \\
Polyester & 0.1768 & 0.2157 & 0.3665 & 0.2085 & 0.2774 & 0.2120 \\
Rayon & 0.1768 & 0.4313 & 0.3665 & 0.4170 & 0.4160 & 0.2120 \\
Silk & 0.3536 & 0.2157 & 0.3665 & 0.2085 & 0.2774 & 0.4240 \\
Spandex & 0.1768 & 0.2157 & 0.3665 & 0.4170 & 0.2774 & 0.3180 \\
Wool & 0.3536 & 0.3235 & 0.1222 & 0.3128 & 0.2774 & 0.3180 \\
\hline
\end{tabular}

The output 1 is shown in Table 10. Table 10 shows the values based on type, criteria, weight, and normalization.

Table 11. Output 2 MOORA Model

\begin{tabular}{lcccccc}
\hline Type & Benefit & Benefit & Benefit & Benefit & Benefit & Cost \\
\hline Normalization & 0.1600 & 0.1500 & 0.1533 & 0.1833 & 0.1733 & 0.1800 \\
Criteria/Alternative & Material & Texture & Color & Characteristic & Comfort & Wearability \\
Acrylic & 0.0283 & 0.0647 & 0.0375 & 0.0764 & 0.0481 & -0.0572 \\
Cotton & 0.0849 & 0.0647 & 0.0375 & 0.0191 & 0.0721 & -0.0763 \\
Linen & 0.0849 & 0.0485 & 0.0375 & 0.0191 & 0.0721 & -0.0572 \\
Mix & 0.0283 & 0.0323 & 0.0562 & 0.0573 & 0.0481 & -0.0572 \\
Nylon & 0.0283 & 0.0323 & 0.0562 & 0.0764 & 0.0240 & -0.0382 \\
Polyester & 0.0283 & 0.0323 & 0.0562 & 0.0382 & 0.0481 & -0.0382 \\
Rayon & 0.0283 & 0.0647 & 0.0562 & 0.0764 & 0.0721 & -0.0382 \\
Silk & 0.0566 & 0.0323 & 0.0562 & 0.0382 & 0.0481 & -0.0763 \\
Spandex & 0.0283 & 0.0323 & 0.0562 & 0.0764 & 0.0481 & -0.0572 \\
Wool & 0.0566 & 0.0485 & 0.0187 & 0.0573 & 0.0481 & -0.0572 \\
\hline
\end{tabular}

The output 2 is shown in Table 11. Table 11 shows the output values based on the type, criteria, weight of update, and update normalization.

Table 12.Output 3 MOORA Model

\begin{tabular}{cccc}
\hline Alternative MCDM & Total & Sort & Alternative MOORA \\
\hline Acrylic & 0.1977 & 0.2595 & Rayon \\
Cotton & 0.2019 & 0.2048 & Linen \\
Linen & 0.2048 & 0.2019 & Cotton \\
Mix & 0.1650 & 0.1977 & Acrylic \\
Nylon & 0.1791 & 0.1841 & Spandex \\
Polyester & 0.1649 & 0.1791 & Nylon \\
Rayon & 0.2595 & 0.1720 & Wool \\
Silk & 0.1551 & 0.1650 & Mix \\
Spandex & 0.1841 & 0.1649 & Polyester \\
Wool & 0.1720 & 0.1551 & Silk \\
\hline
\end{tabular}

The output 3 is shown in Table 12. Table 12 shows Rayon as the best alternative in the MOORA Model. The total values in Table 12 are sorted by Sort based on the Descending process. The best results is the highest 
value, which is Alternative Rayon with a value of 0.2595 . Therefore, Rayon was chosen as the best alternative from alternatives based on the MOORA Model.

\subsection{SAW Model}

The SAW Model uses alternatives based on Table 1 and attribute-based on Table 2. Step 1: determine criteria and alternatives based Equation $(1,2,3)$ which can be seen in Table 1 and Table 2. Step 2: determine the the factor and weight factor with the total weight of the factor is 1 . Input weight based on Equation (4) and normalization are shown in Table 2. Step 3: determine the type of weight factor by the type of benefit (weight factor criteria with maximum value) and type of cost (weight factor criteria with minimum value). Criteria with the types of benefits are material, texture, color, characteristic, and comfort. Criteria with the type of cost is wearability. Types of Benefits and costs display type in Table 9. Step 4: enter the value of each criterion for each alternative based on the decision matrix (Table 3). Input value in SAW can be seen in Table 13. Table 13 shown value for each alternative based on criteria.

Table 13. Input SAW Model

\begin{tabular}{lcccccc}
\hline Type & Benefit & Benefit & Benefit & Benefit & Benefit & Cost \\
\hline Normalization & 0.1600 & 0.1500 & 0.1533 & 0.1833 & 0.1733 & 0.1800 \\
Divider & 3 & 4 & 3 & 4 & 3 & 2 \\
Criteria/Alternative & Material & Texture & Color & Characteristic & Comfort & Wearability \\
Acrylic & 1 & 4 & 2 & 4 & 2 & 3 \\
Cotton & 3 & 4 & 2 & 1 & 3 & 4 \\
Linen & 3 & 3 & 2 & 1 & 3 & 3 \\
Mix & 1 & 2 & 3 & 3 & 2 & 3 \\
Nylon & 1 & 2 & 3 & 4 & 1 & 2 \\
Polyester & 1 & 2 & 3 & 2 & 2 & 3 \\
Rayon & 1 & 4 & 3 & 4 & 3 & 2 \\
Silk & 2 & 2 & 3 & 2 & 2 & 4 \\
Spandex & 1 & 2 & 3 & 4 & 2 & 3 \\
Wool & 2 & 3 & 1 & 3 & 2 & 3 \\
\hline
\end{tabular}

Step 5: rank the divider value based on the maximum value of the type of benefit and the minimum value in the cost in Excel formula $=\operatorname{IF}(\mathrm{D} \$ 5="$ cost", MIN(D\$9:D\$18), MAX(D\$9:D\$18)) material criteria with value $=3$. The same method is also applied to the Texture criteria up to Wearability criteria. Ratings are shown in Table 14.

Table 14. Rating

\begin{tabular}{lcccccc}
\hline Criteria/Alternative & Material & Texture & Color & Characteristic & Comfort & Wearability \\
\hline Acrylic & 1 & 4 & 2 & 4 & 2 & 3 \\
Cotton & 3 & 4 & 2 & 1 & 3 & 4 \\
Linen & 3 & 3 & 2 & 1 & 3 & 3 \\
Mix & 1 & 2 & 3 & 3 & 2 & 3 \\
Nylon & 1 & 2 & 3 & 4 & 1 & 2 \\
Polyester & 1 & 2 & 3 & 2 & 2 & 3 \\
Rayon & 1 & 4 & 3 & 4 & 3 & 2 \\
Silk & 2 & 2 & 3 & 2 & 2 & 4 \\
Spandex & 1 & 2 & 3 & 4 & 2 & 3 \\
Wool & 2 & 3 & 1 & 3 & 2 & 3 \\
\hline Rating & 3 & 4 & 3 & 4 & 3 & 2 \\
\hline
\end{tabular}

Table 14 shows the ranking for types of benefits (max. value) and type of costs (min. value). Rating value for each criterion toward each alternative. 
Step 6: normalize the value of each criterion for the value of each alternative for the benefits and costs based on the type of Equation (11) in the formula Excel =IF(D \$5="cost",MIN(D\$9:D\$18)/D9,D9/MAX(D\$9: D\$18)) for Alternative Acrylic with a value 0.3333. The same method is also used in Alternative Cotton to Alternative Wool. The output is shown in Table 15. Table 15 shows the normalization of the value updates for each criterion for each alternative.

Table 15. Output 1 SAW Model

\begin{tabular}{lcccccc}
\hline Criteria/Alternative & Material & Texture & Color & Characteristic & Comfort & Wearability \\
\hline Acrylic & 0.3333 & 1 & 0.6667 & 1 & 0.6667 & 0.6667 \\
Cotton & 1 & 1 & 0.6667 & 0.2500 & 1 & 1 \\
Linen & 1 & 0.7500 & 0.6667 & 0.2500 & 1 & 0.6667 \\
Mix & 0.3333 & 0.5000 & 1 & 0.7500 & 0.6667 & 0.6667 \\
Nylon & 0.3333 & 0.5000 & 1 & 1 & 0.3333 & 1 \\
Polyester & 0.3333 & 0.5000 & 1 & 0.5000 & 0.6667 & 0.6667 \\
Rayon & 0.3333 & 1 & 1 & 1 & 1 & 1 \\
Silk & 0.6667 & 0.5000 & 1 & 0.5000 & 0.6667 & 1 \\
Spandex & 0.3333 & 0.5000 & 1 & 1 & 0.6667 & 0.6667 \\
Wool & 0.6667 & 0.7500 & 0.3333 & 0.7500 & 0.6667 & 0.6667 \\
\hline
\end{tabular}

Step 7: calculate the ranking value of each alternative based on Equation (12) in Excel formula $=(\mathrm{D} \$ 6 * \mathrm{D} 22)+(\mathrm{E} \$ 6 * \mathrm{E} 22)+\left(\mathrm{F} \$ 6^{*} \mathrm{~F} 22\right)+(\mathrm{G} \$ 6 * \mathrm{G} 22)+\left(\mathrm{H} \$ 6^{*} \mathrm{H} 22\right)+\left(\mathrm{I} \$ 6^{*} \mathrm{I} 22\right)$ for Alternative Acrylic with a value of 0.7244 . The same method is also used in Alternative Cotton to Alternative Wool. Output shown in Table 16.

Table 16. Output 2 SAW Model

\begin{tabular}{cccc}
\hline Alternative MCDM & Total & Sort & Alternative SAW \\
\hline Acrylic & 0.7244 & 0.8932 & Rayon \\
Cotton & 0.7213 & 0.7244 & Acrylic \\
Linen & 0.7138 & 0.7213 & Cotton \\
Mix & 0.6546 & 0.7138 & Linen \\
Nylon & 0.7027 & 0.7027 & Nylon \\
Polyester & 0.6088 & 0.7005 & Spandex \\
Rayon & 0.8932 & 0.6546 & Mix \\
Silk & 0.6322 & 0.6433 & Wool \\
Spandex & 0.7005 & 0.6322 & Silk \\
Wool & 0.6433 & 0.6088 & Polyester \\
\hline
\end{tabular}

Step 8: calculate the final value of each criterion for each alternative. The total values in Table 16 are sorted by Sort based on the Descending process. The best result is the highest value, which is Alternative Rayon with a value of 0.8932 . Rayon was chosen as the best alternative from alternatives based on the SAW Model.

\subsection{WP Model}

The WP Model uses alternatives based on Table 1 and attribute-based on Table 2. Step 1: determine criteria and alternatives based Equation $(1,2,3)$ which can be seen in Table 1 and Table 2. Step 2: determine a scale of 0 to 100 and the total based on priority criteria using random numbers with a value of 2,400 for material criteria, texture with a value of 2.2500 , up to wearability criteria with value 2.2700 with a total $=15$ based on Equation (4) shown in Table 2. Step 3: determine the factors and weight factors with the total weighting factor being 1 by dividing the scale value by the total scale value shown in Table 2. Step 4: enter the value of each criterion for each alternative based on the decision matrix (Table 3). The Input values in the WP model can be seen in Table 17. Table 17 shows the values for each alternative based on type, criteria, weight, and normalization. 
Table 17. Input WP Model

\begin{tabular}{|c|c|c|c|c|c|c|}
\hline Type & Benefit & Benefit & Benefit & Benefit & Benefit & Cost \\
\hline Normalization & 0.1600 & 0.1500 & 0.1533 & 0.1833 & 0.1733 & 0.1800 \\
\hline Weight & 2.400 & 2.2500 & 2.3000 & 2.7500 & 2.6000 & 2.7000 \\
\hline Rank & 0.1600 & 0.1500 & 0.1533 & 0.1833 & 0.1733 & -0.1800 \\
\hline Criteria/Alternative & Material & Texture & Color & Characteristic & Comfort & Wearability \\
\hline Acrylic & 1 & 4 & 2 & 4 & 2 & 3 \\
\hline Cotton & 3 & 4 & 2 & 1 & 3 & 4 \\
\hline Linen & 3 & 3 & 2 & 1 & 3 & 3 \\
\hline Mix & 1 & 2 & 3 & 3 & 2 & 3 \\
\hline Nylon & 1 & 2 & 3 & 4 & 1 & 2 \\
\hline Polyester & 1 & 2 & 3 & 2 & 2 & 3 \\
\hline Rayon & 1 & 4 & 3 & 4 & 3 & 2 \\
\hline Silk & 2 & 2 & 3 & 2 & 2 & 4 \\
\hline Spandex & 1 & 2 & 3 & 4 & 2 & 3 \\
\hline Wool & 2 & 3 & 1 & 3 & 2 & 3 \\
\hline
\end{tabular}

Step 5: calculate alternative preference values based on Equation $(13)$ in the Excel formula $=\left(\mathrm{C} 9^{\wedge} \mathrm{C} \$ 20\right)$ $\left.*\left(\mathrm{D} 9^{\wedge} \mathrm{D} \$ 20\right)^{*}\left(\mathrm{E} 9^{\wedge} \mathrm{E} \$ 20\right)^{*}\left(\mathrm{~F} 9^{\wedge} \mathrm{F} \$ 20\right)^{*}\left(\mathrm{G} 9^{\wedge} \mathrm{G} \$ 20\right)\right)^{*}\left(\mathrm{H} 9^{\wedge} \mathrm{H} \$ 0\right)$ for Alternative Acrylic with a value of 1.6336. The same method is also used in Alternative Cotton to Alternative Wool. The Output shown in Table 18.

Table 18. Output WP Model

\begin{tabular}{ccccc}
\hline Alternative MADM & $\mathrm{S}$ & $\mathrm{V}($ Total) & Sort & Alternative WP \\
\hline Acrylic & 1.6336 & 0.1046 & 0.1285 & Rayon \\
Cotton & 1.5386 & 0.0986 & 0.1046 & Acrylic \\
Linen & 1.5520 & 0.0994 & 0.1004 & Spandex \\
Mix & 1.4862 & 0.0952 & 0.0994 & Linen \\
Nylon & 1.4945 & 0.0957 & 0.0986 & Cotton \\
Polyester & 1.3797 & 0.0884 & 0.0957 & Nylon \\
Rayon & 2.0061 & 0.1285 & 0.0955 & Wool \\
Silk & 1.4638 & 0.0938 & 0.0952 & Mix \\
Spandex & 1.5667 & 0.1004 & 0.0938 & Silk \\
Wool & 1.4911 & 0.0955 & 0.0884 & Polyester \\
\hline
\end{tabular}

Step 6: calculate the vector value $\left(V_{i}\right)$ for each alternative based on Equation (14) in the Excel formula $=\mathrm{J} 9 /$ (J\$9+J\$10+J\$11+J\$12+J\$13+J\$14+J\$15+J\$16+J\$17+J\$18) for Alternative Acrylic with a value of 0.1046. The same method is also used in alternative Cotton to Alternative Wool. The Output is shown in Table 18. Step 7: calculate the final value of each criterion for each alternative. The total values in Table 18 are sorted by Sort based on the Descending process. The best result with the highest value is Alternative Rayon with a value of 0.1285. Therefore, Rayon was chosen as the best alternative from alternatives based on the WP Model.

\subsection{Sustainable Fashion}

The use of the five models as a hybrid approach is to determine categories of materials clothing and criterion clothing. The hybrid approach is a process for decision making using multiple alternative, multiple criterion, and multiple objective with maximum objective function (benefit) and minimum objective function (cost) for sustainable fashion. Sustainable fashion is part of a developing design philosophy with the aim of creating a system that can reduce environmental damage due to the production and consumption of clothing. Table 19 shows comparisons based on the type of benefit-cost and the highest value of each method and rank alternatives. Table 20 shows the methods and formulas by using an Excel application. Table 21 shows MADM using hybrid approach for sustainable fashion. 
Table 19. Result of Hybrid Approach

\begin{tabular}{clllll}
\hline & SMART & MFEP & MOORA & SAW & WP \\
\hline No. & Non Benefit Cost & Non Benefit Cost & Benefit Cost & Benefit Cost & Benefit Cost \\
\hline 1 & Rayon & Rayon & Rayon & Rayon & Rayon \\
2 & Cotton & Cotton & Linen & Acrylic & Acrylic \\
3 & Acrylic & Acrylic & Cotton & Cotton & Spandex \\
4 & Spandex & Spandex & Acrylic & Linen & Linen \\
5 & Silk & Silk & Spandex & Nylon & Cotton \\
6 & Linen & Linen & Nylon & Spandex & Nylon \\
7 & Wool & Wool & Wool & Mix & Wool \\
8 & Nylon & Mix & Mix & Wool & Mix \\
9 & Polyester & Nylon & Polyester & Silk & Silk \\
10 & Mix & Polyester & Silk & Polyester & Polyester \\
\hline
\end{tabular}

Table 20. Method Formula Excel and Description

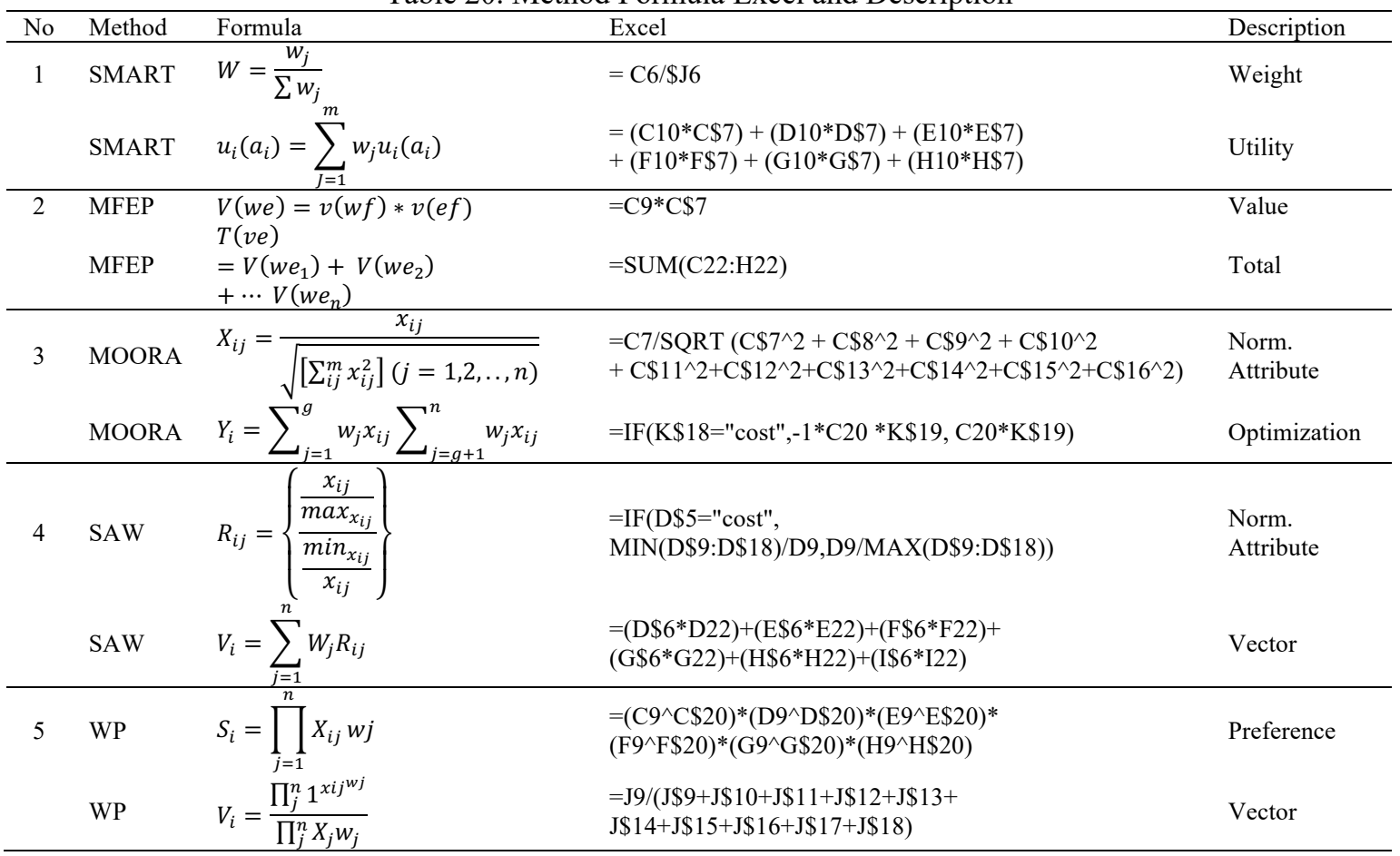

Table 21. MADM using Hybrid Approach

\begin{tabular}{ccccc}
\hline Method & Multi Attribute & Multi Objective & Multi Criteria & Multi Alternative \\
\hline SMART & Multi Alternative & Maximum Objective (Benefit) & Material & Acrylic \\
MFEP & Multi Criteria & Minimum Objective (Cost) & Texture & Cotton \\
MOORA & Multi Objective & - & Color & Linen \\
SAW & - & - & Characteristic & Mix \\
WP & - & - & Comfort & Nylon \\
- & - & - & Wearability & Polyester \\
- & - & - & - & Rayon \\
- & - & - & - & Silk \\
- & - & - & - & Spandex \\
- & - & - & - & Wool \\
\hline
\end{tabular}




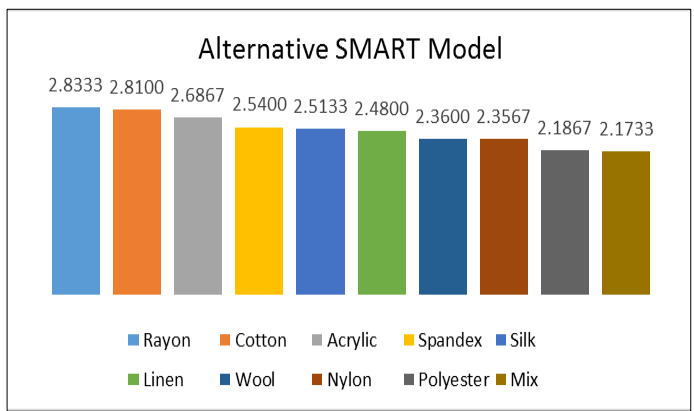

Figure 2. Graphic of Alternative SMART Model.

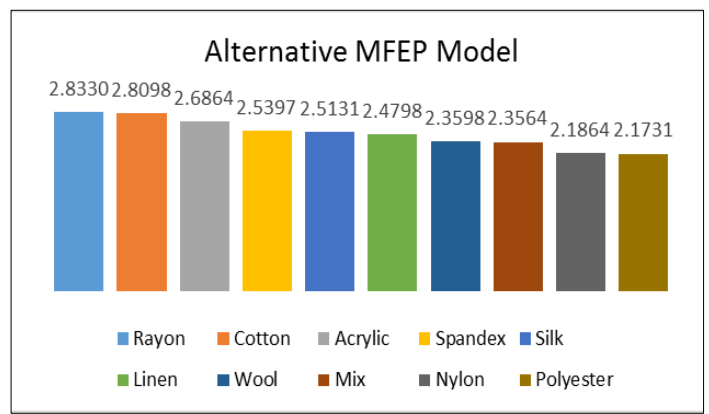

Figure 3. Graphic of Alternative MFEP Model.

Figure 2 shows the sort value for each alternative in the SMART Model. Figure 3 shows the sort value for each alternative in the MFEP Model.



Figure 4. Graphic of Alternative MOORA Model.

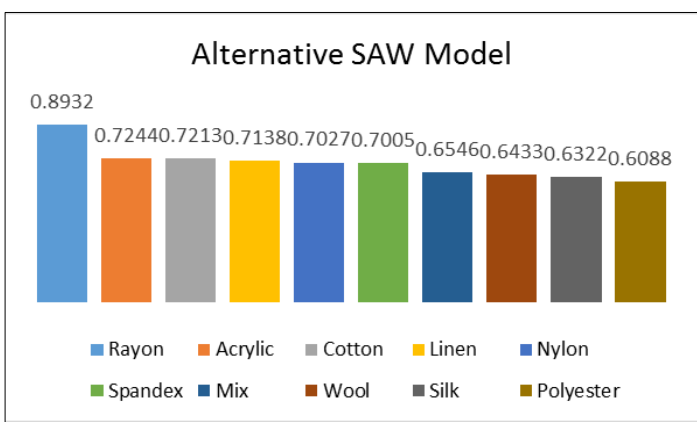

Figure 5. Graphic of Alternative SAW Model.

Figure 4 shows the sort value for each alternative in the MOORA Model. Figure 5 shows the sort value for each alternative in the SAW Model. Figure 6 shows the sort value for each alternative in the WP Model.

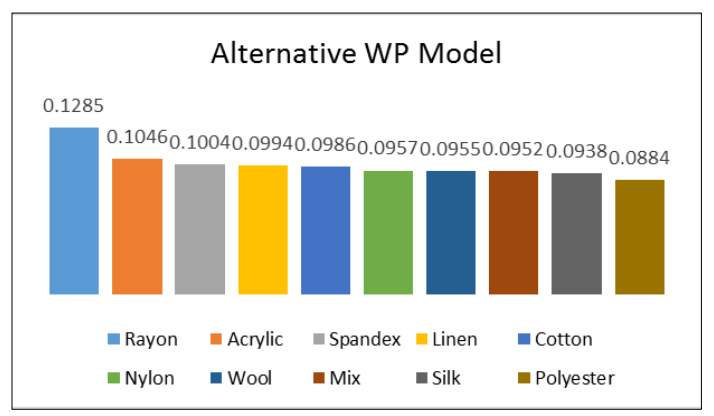

Figure 6. Graphic of Alternative WP Model.

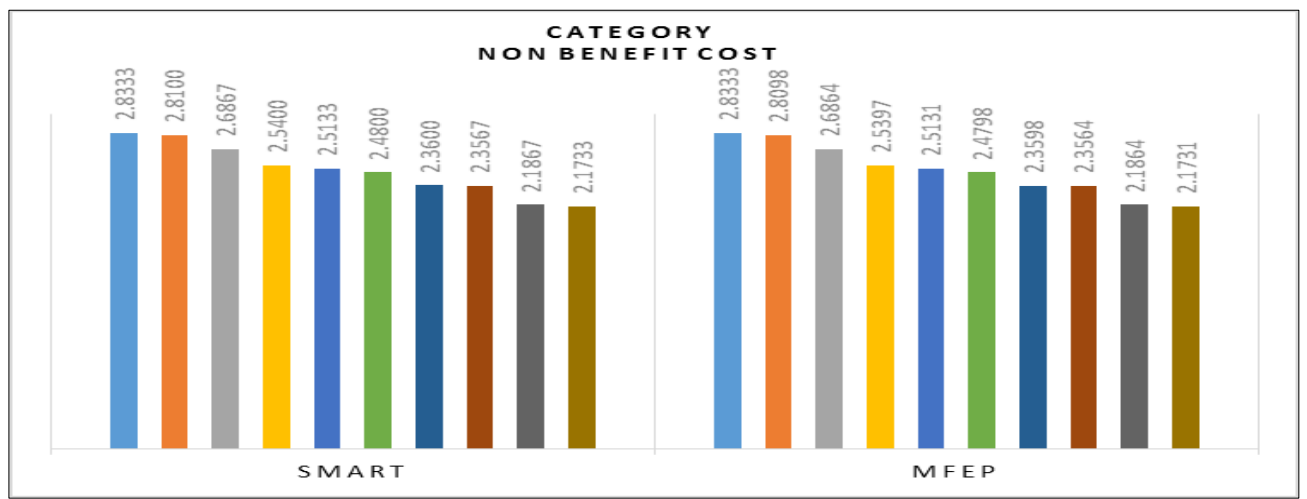

Figure 7. Graphic of Non Benefit Cost.

Figure 7 shows the sort value for each alternative in SMART and MFEP based on type non-benefit and cost. Based on Figure 7, the type of non-benefit cost (maximum objective function $=$ benefit), the rayon is the best 
alternative with the highest value. Based on the maximum objective function (benefit), the rayon is the best alternative with optimal value. This means that the use of rayon based on the type of benefit can be maximized (maximum objective function) in one process simultaneously.

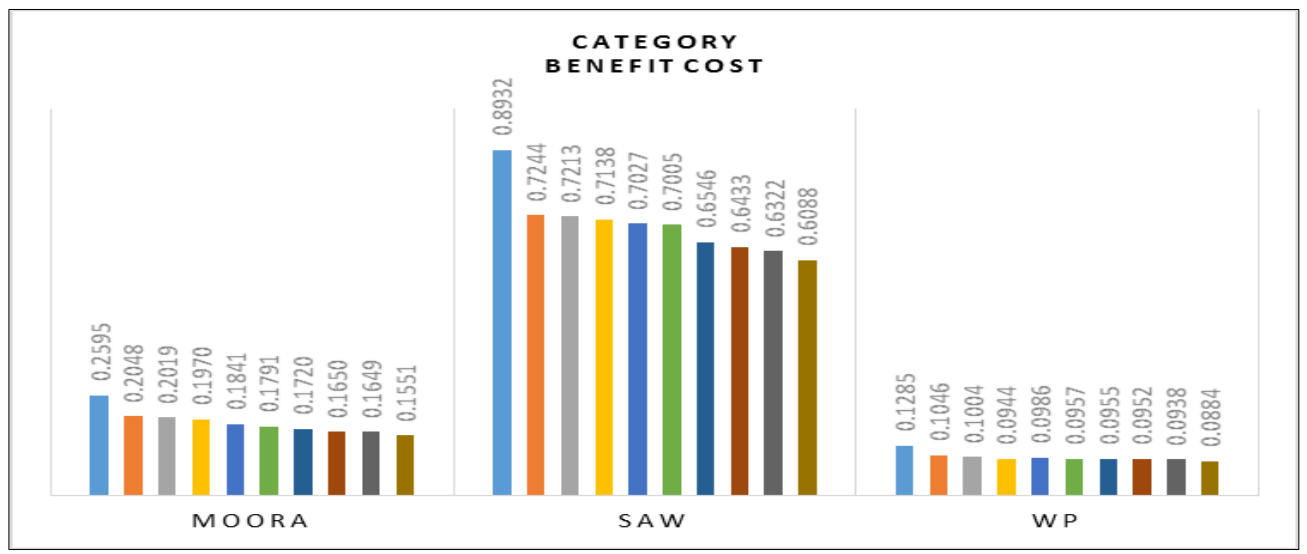

Figure 8. Graphic of Benefit Cost.

Fig. 8 shows sort value for each alternative in MOORA, SAW, and WP based on type benefit and cost. Based on the type of benefit and the type of cost, the rayon is the best alternative with the highest value. Based on the maximum objective function and minimum objective function, the rayon is the best alternative with optimal value. This means that the use of rayon based on the type of benefit can be maximized (maximum objective function = benefit) and based on the type of cost can be minimized (minimum objective function $=$ cost) in one process simultaneously.

\section{CONCLUSION}

Multi-Attribute Decision Making using Hybrid Approach (combination of SMART Model, MFEP Model, MOORA Model, SAW Model, and WP Model) for Sustainable Fashion resulted in the best alternative which is rayon. The selection of the SMART model with the best alternative also resulted in rayon with the highest value (2.8333). The selection of the MFEP model with the best alternative resulted in rayon with the highest value (2.8330). The selection of the MOORA model with the best alternative is rayon with the highest value $(0.2595)$. The selection of the SAW model with the best alternative is rayon with the highest value (0.8932). The selection of WP Model with the best alternative is rayon with the highest value (0.1285). SMART and MFEP are used for criteria with a maximum objective function (benefit). MOORA, SAW, and WP are used for criteria with minimum objective functions (cost). Multi-attribute decision-making using Hybrid Approach with multi-objective (benefit and cost) was successfully carried out and the results can be used as data sources in decision making for sustainable fashion. MADM by using hybrid approach for sustainable fashion yields the best alternative (rayon) for consumption and production for the middle-class population in Indonesia. Subsequent research will be MADM using AHP, TOPSIS, PROMETHEE, and VIKOR for SecondHand Selection.

\section{REFERENCES}

[1] F. Harris, H. Roby, and S. Dibb, "Sustainable Clothing: Challenges, Barriers and Interventions for Encouraging more Sustainable Consumer Behaviour," vol. 40, no. 3, pp. 309-318, 2016. doi: http: //dx.doi.org /doi: 10.1111/ijcs.12257

[2] Adriyendi, "Fuzzy Logic using Tsukamoto Model and Sugeno Model on Prediction Cost," International Journal of Intelligent Systems and Applications, vol. 10, no. 6, pp. 13-21, Jun 2018. doi:https://10.5815/ijisa.2018.06.02

[3] A. Qastarin and M. C. A. Siagian, "Organza Exploration as the Main Material in Party Dress Design," e-Proceedings of Art \& Design, vol. 6, no. 1, pp. 273-293, 2019.

[4] W. Hadikurniawati, E. Winarno, T. D. Cahyono, and D. Abdullah, "Comparison of AHP-TOPSIS Hybrid Methods,WP, and SAW for Multi-Attribute Decision-Making to Select the Best Electrical Expert," IOP Conf. Series: Journal of Physics: Conf. Series 1114,pp. 1-12, 2018. doi:http:/10.1088/1742-6596/1114/1/012100

[5] A. B. Marendra, D. Nugroho, and I. A. Prabowo, "Classification of Futsal Players uses the Simple Multi-Attribute Rating Technique Method," Journal of TIKomSiN, vol. 6, no. 2, 22-30, Oct 2018, doi:https: //doi.org /10.30646/tikomsin.v6i2.377

[6] R. Sulaehani, "Application of the Multifactor Evaluation Process Method in the Decision Support System for Providing Family Latrine Aid at Dulomo Village office," Tecnoscienza, vol. 3, no. 2, pp. 161-176, Apr 2019.

[7] E. G. Genc and O. D. Basar, "Comparison of Country Ratings of Credit Rating Agencies with MOORA Method," Business and Economics Research Journal, vol. 10, no. 2, pp. 391-404, 2019. doi:https /:10.20409/berj.2019.175 
[8] F. B. Hartono and H. J. Prasetyo, "Decision Support System using the Simple Additive Weighting Method to Determine the Superior Products in Mount of Kidul Regency," Journal of Teknika, vol. 11, no. 1, pp. 1071-1076, 2019.

[9] Mujahidin, A. B. Purba and T. Agustian, " Implementation of the Weighted Product Method in Decision Support Systems for the Production of Not Good Materials (ng). ILKOM Journal of Scientific, vol. 11, no. 1, pp. 25-33, Apr 2019. doi:http://dx.doi.org/10.33096/ilkom.v11i1.388.25-33

[10] R. Y. Hayuningtyas, “Application of Naïve Bayes Algorithm for Recommended Women's Clothing,” Journal of Informatics, vol. 6, no. 1, pp. 8-22, Apr 2019. Retrieved from http:// ejournal. bsi.ac.id/ ejurnal /index.php/ji/article/view/4685

[11] Y. Nuriyati, and O. O. Sharif, "Analysis of Customer Value Index in Choosing Women's Clothing Attributes in Indonesia. e-Proceeding of Management, vol. 6, no. 1, pp. 106-114, 2019.

[12] R. Rachman, "Application of the AHP Method to Determine the Quality of Apparel in the Garment Industry," Journal of Informatics, vol. 6, no. 1, pp. 1-8, 2019. Retrieved from http://ejournal.bsi.ac.id /ejurnal/ index.php /ji/article/view/4389

[13] J. Kittur, "Optimal Generation Evaluation using SAW, WP, AHP, and Promethee Multi-Criteria Decision-Making Techniques," IEEE Intl. Conf. on Technological Advancements in Power \& Energy, pp. 304-309, 2015.

[14] S. Khadarlina, "Decision Support System for Coastal Tourist Area Sustainability using Mfep and Smart Methods," Thesis, Tanjung Pinang, Informatics Engineering, Faculty of Engineering, Raja Ali Haji Maritime University. Retrieved Jun 2019

[15] Adriyendi "Multi-Attribute Decision Making using Simple Additive Weighting and Weighted Product in Food Choice," International Journal of Information Engineering and Electronic Business, vol. 6, no. 2, pp. 8-12, Nov 2015. doi:https://10.5815/ijieeb.2015.06.02

[16] H. Priatna, Dedih, and J. Mulyana, "Comparison of Smart and SAW Methods in Determining Web-based Permanent Employees. UNSIKA Syntax Journal of Informatics, vol. 5, no. 1, pp. 53-85, 2016.

[17] A. K. Vadreas, R. Turaina, and S. Ardiansyah, "Decision Support System for Determining Housing Development Funds is not Egible by using the Mfep Method. Journal of TEKNOIF, vol. 6, no. 1, pp. 18-23, Apr 2018. doi:http://10.21063/JTIF.2018.V6.1.18-23

[18] Ramadiani, F. P. K. Rani, D. M. Khairina, \& H. R. Hatta, "Decision Support System by using the Moora Method for Pandega Scout Selection," Journal of Information Technology and Computer Science, vol. 6, no. 2, pp. 899-906, 2019. doi:http://0.25126/jtiik.201961284

[19] V. Amalia, D. Syamsuar, and L. Atika, "Comparison of WP, SAW, and WASPAS in Determining Scholarship Recipients Tracking Interests and Capabilities," Informatika Journal, vol. 6, no. 1, pp. 114-121, 2019. Retrieved from http://ejournal.bsi.ac.id/ejurnal/index.php/ji/article/view/5511

[20] S. R. Arifin and J. S. Mintamanis, Josua Crishan, "Decision Support System for Determining Thesis Supervisior using a Weighted Product Method," JOIN (Journal Online Informatika), vol. 3, no. 2, pp. 80-85, Dec 2018. doi:https: // 10.15575 /join.v3i2.230

[21] C.E. Henninger, P. J. Alevizou, and C. J. Oates, "What is sustainable Fashion?," Journal of Fashion Marketing and Management, 1-22, 2016. doi:https://doi.org/10.1108/JFMM-07-2015-0052 